\section{Sentimentos de profissionais dos serviços de pronto-socorro pediátrico: reflexões sobre o burnout}

\author{
Feelings of paediatric emergency service \\ professionals: reflexions on burnout
}

Katia Virginia de Oliveira Feliciano 1

Maria Helena Kovacs 2

Sílvia Wanick Sarinho 3
1 Grupo de Estudos em Avaliação de Saúde. Diretoria de Pesquisa. Instituto Materno Infantil Prof. Fernando Figueira, IMIP. Rua dos Coelhos, 300. Recife, PE, Brasil. CEP: 50.070-550.

2,3 Grupo de Avaliação dos Serviços de Saúde. Faculdade de Ciências Médicas. Universidade de Pernambuco. Recife, PE, Brasil

\begin{abstract}
Objectives: determine the feelings of emergency services (ER) pediatricians when facing the circumstances of their work, focusing on burnout components: emotional exhaustion, lack of personal involvement and detachment.

Methods: qualitative research performed in the city of Recife from March to July 2003 in five major public hospitals, using content analysis to understand the "nucleus of meaning" of the messages of 40 semistructured interviews with pediatricians and seven emergency nurses.

Results: these reports convey different feelings: fatigue, exhaustion, anguish and anger stemming from overwork and resources constraints in the face of circumstances involving lives at risk, permeated by the satisfaction of love for the job and self-recognition; fear of committing fatal mistakes; lack of professional qualification when comparing wages with responsibility and effort; exposure to risk of aggression and lawsuits which feed on the lack of hope and increased vulnerability; and commitment to the job. Among recently graduated doctors there's disbelief in change and the wish of giving up.

Conclusions: notwithstanding chronic job stress, healthcare professionals in ER keep up with their commitment of trying to solve day to day problems. There's a trend for emotional exhaustion, depression and feelings of inadequacy and failure reinforcing the need of health promotion and prevention in the work environment.
\end{abstract}

Key words Professional practice, Job satisfaction, Employee performance appraisal, Emotions

\section{Resumo}

Objetivos: conhecer os sentimentos de profissionais dos serviços de pronto-socorro infantil diante das situações de trabalho, focalizando os componentes do burnout: exaustão emocional, falta de envolvimento pessoal e despersonalização.

Métodos: pesquisa qualitativa realizada, na cidade do Recife, de março a julho de 2003, em cinco unidades públicas de referência, utilizando análise de conteúdo para compreender os "núcleos de sentido" das mensagens de 40 entrevistas semi-estruturadas com pediatras e sete enfermeiras da urgência/emergência.

Resultados: nesses relatos convivem sentimentos díspares: cansaço, esgotamento, angústia e revolta pela sobrecarga e limitações dos recursos frente às situações que envolvem risco de vida, permeados pela satisfação de gostar do que fazem e reconhecimento da própria utilidade; temor de cometer enganos fatais; desqualificação profissional quando comparam remuneração com responsabilidade e esforço empregado; exposição ao risco de agressão e indiciamento judicial alimentando desesperança e vulnerabilidade; e vínculo afetivo com trabalho. Esboçam-se, sobretudo entre médicos com menor tempo de formados, o descrédito nas possibilidades de mudanças e a vontade de desistir.

Conclusões: apesar do estresse laboral crônico, os profissionais entrevistados mantêm o compromisso de contribuir na solução dos problemas cotidianos. Existe tendência para exaustão emocional, desânimo e sentimentos de inadequação e fracasso, reforçando a importância da promoção e prevenção em saúde no ambiente de trabalho.

Palavras-chave Prática profissional, Satisfação no emprego, Avaliação de desempenho, Emoções 


\section{Introdução}

O processo de implantação do Sistema Único de Saúde (SUS) é uma árdua construção coletiva que compromete sujeitos diversos em contínua e imprescindível interação material e simbólica, requerendo uma maior compreensão das expectativas envolvidas nas relações entre os serviços e os usuários, assim como entre os profissionais e os serviços. ${ }^{1}$ Portanto, como salienta Merhy, 2 é imprescindível estar atento ao fato de que os esforços das reformas macro-estruturais têm pouca utilidade quando se desconsidera o lugar estratégico de mudança, isto é, as micropolíticas dos processos de trabalho que expressam os modos de sentir, representar e vivenciar as necessidades no cotidiano das organizações.

Os sentidos assumidos pelo trabalho para aqueles que o realizam são passíveis de compreensão a partir das idéias e valores relativos aos conteúdos das tarefas, modos operatórios, normas e padrões estabelecidos, atribuição de competências e relações inter-hierárquicas e interpessoais, em tempos e espaços determinados. Esses sentidos aclaram as conexões entre os componentes internos das situações de trabalho, as transformações tecnológicas e organizacionais alcançadas e perseguidas pela atenção em saúde e as condições de vida. Nos serviços de saúde, os significados e valores constitutivos das práticas de distintos grupos profissionais operam simultaneamente, de forma articulada ou não, solicitando a negociação de interesses.2,3

Ao traçar uma aproximação ao dia-a-dia dos hospitais de pronto-socorro infantil é possível encontrar um trabalho que entrelaça a responsabilidade com pacientes graves e seus familiares, a grande demanda, a insuficiência de recursos materiais e humanos, os baixos salários, os múltiplos empregos e conseqüente cansaço, motivando uma contínua tensão emocional. Nesse contexto, manifestam-se sentimentos (aspirações dirigidas à satisfação das necessidades) e desejos (percepções das possibilidades de satisfazer essas necessidades) que não expressam exclusivamente uma necessidade particular, visto que podem ser compartilhados por outros membros das equipes. A experiência subjetiva e os significados intersubjetivos associados ao cuidado em saúde repercutem na vida mental dos profissionais $4-6$ e, por conseguinte, nas suas respostas diante das situações de trabalho, favorecendo ou prejudicando os processos de organização das práticas de saúde e a qualidade da atenção prestada à população.7,8

Segundo Seligmann-Silva, 4 o ritmo acelerado das transformações do trabalho tem propiciado um reconhecimento crescente da sua importância como mediador entre as diferentes instâncias sociais e a saúde humana. Nas pesquisas sobre essa temática, sobressaem-se três correntes teóricas de distintas áreas do conhecimento, as quais se fundamentam em estudos: a) psicofisiológicos, focalizando-se no conceito de estresse; b) da psicodinâmica do trabalho que integra o referencial psicanalítico à análise das vivências no mundo do trabalho, ressaltando o conceito de sofrimento mental; e c) da dinâmica da dominação que entremeia as relações de poder, centrando-se no conceito de perdas que podem ser concretas, potenciais ou simbólicas, e que têm a possibilidade de abranger, simultaneamente, a dimensão biológica, psíquica e social.

A partir das pesquisas sobre o estresse, Freudenberg, em 1974, citado por Farber, 9 iniciou os estudos sobre o burnout, considerado clinicamente como um estado de exaustão resultante do excesso de trabalho, pondo à margem as próprias necessidades. Farber ${ }^{9}$ compilou outras abordagens: a psicossocial, de Malasch e Jackson, que entendem a síndrome como uma reação à tensão emocional crônica a que estão submetidos os profissionais que lidam com problemas de outras pessoas, envolvendo exaustão emocional (perda ou desgaste dos recursos emocionais), despersonalização (sentimentos e atitudes negativas) e falta de realização pessoal (sentimentos de inadequação e fracasso); a organizacional, de Cherniss, que está atenta aos modos como os mundos prático-simbólicos coexistentes na instituição afetam as pessoas em seus trabalhos; e a sócio-histórica, de Sarason, que ressalta a relação entre contexto, indivíduo e organização.

$\mathrm{Na}$ tentativa de integrar essas perspectivas, Farber ${ }^{9}$ define burnout como uma síndrome do trabalho que se origina da discrepância da percepção entre esforço e conseqüência, percepção essa influenciada por aspectos individuais, organizacionais e sociais. A exaustão emocional é considerada como a primeira etapa e a dimensão central dessa síndrome, constituindo-se como a gênese das demais manifestações. Por outro lado, as mudanças nas abordagens das inter-relações entre trabalho e saúde, fruto da interlocução entre as correntes teóricas mencionadas, podem ser apreendidas nas referências ao sofrimento mental e às perdas como componentes do burnout, em um estudo realizado com profissionais de educação do Brasil.5,10-12

Para Codo e Vasques-Menezes 5 é impossível saber desde quando essa síndrome existe, logo, a importância dos estudos de Freudenberg foi nomear um sentimento que já estava presente, criando condições para entendê-lo, enfrentá-lo, conhecer 
seus limites. Todavia, os autores destacam que a acentuação do conflito entre a exigência de um trabalho qualificado e as possibilidades reais de sua execução, sobretudo nas profissões das áreas de educação e saúde, as quais requerem atenção contínua e grande responsabilidade a cada gesto no trabalho, tornou o burnout em um fenômeno de elevada prevalência, com repercussões nas relações familiares e sociais

Multifacetado, o burnout só pode ser compreendido à medida que se elucida a dinâmica da sua complexidade, visto que inclui as percepções das condições de trabalho, riscos e perigos, sobrecarga, desempenho dos papéis e importância social do trabalho, as relações interpessoais, a adoção de novas tecnologias, o acesso à capacitação, a participação no processo decisório, as relações com o entorno, a remuneração, os múltiplos empregos e os valores conflitantes. A esses, devem ser acrescidos, entre outros elementos, idade, sexo, tempo de exercício profissional, sentimentos de auto-eficácia, centralidade do trabalho, estratégias utilizadas para lidar com os problemas do cotidiano e disponibilidade de uma rede de relacionamentos que forneça suporte social. $5,7,8,10-14$

Nos últimos vinte anos, pesquisas têm mostrado a importância da distribuição mundial do burnout entre médicos e enfermeiras, 7,8,15 com altos níveis de exaustão emocional, despersonalização e falta de realização pessoal sendo constatados, especialmente, entre os trabalhadores de saúde que atuavam nos serviços de emergência, $15-17$ nas unidades de terapia intensiva7,18,19 e na assistência aos portadores de câncer.7,15 Em uma evidência de preocupação, o manual de orientações psicossociais produzido pela Sociedade Internacional de Oncologia Pediátrica20 contém informações sobre a prevenção do burnout entre os membros das equipes de saúde que assistem crianças com câncer. No Brasil, os poucos estudos desenvolvidos identificaram a ocorrência dessa síndrome em profissionais de saúde.13,21

Em um contexto onde é difícil a interlocução entre os princípios norteadores do SUS e a realidade dos serviços de saúde na atenção à população infantil, as respostas dos profissionais participantes do presente estudo à questão sobre "... como se sentem diante do trabalho que realizam no atendimento de urgência e emergência" motivaram a busca de uma maior compreensão do sofrimento e das perdas que perpassam as vivências relatadas, tendo como referência os três componentes do burnout: exaustão emocional, sentimentos e atitudes negativas diante do trabalho e sentimentos de inadequação e fracasso. Em sintonia com a aspiração de resgatar a dimensão relacional das práticas de saúde, 22 espera-se contribuir para o fortalecimento da importância do cuidado com a qualidade de vida daquele que cuida, fornecendo subsídios que permitam aprimorar o processo de humanização do trabalho como parte indissociável da humanização da atenção em saúde.

\section{Métodos}

Esta pesquisa qualitativa é parte de um estudo de caso múltiplo com dois níveis de análise: 23 a) o acesso das crianças à atenção básica de saúde e adequação da demanda à densidade tecnológica dos serviços; e b) as percepções e práticas dos responsáveis pelas crianças e de profissionais de saúde acerca da atenção à saúde. Participaram cinco unidades públicas, da cidade do Recife, Pernambuco, Brasil, que atuam como referência para urgência/emergência pediátrica: Hospital de Pediatria Helena Moura e Hospital de Pediatria Maria Cravo Gama, serviços de atenção secundária cuja demanda procede do Recife e da Região Metropolitana; Hospital Barão de Lucena, Instituto Materno Infantil Professor Fernando Figueira, (IMIP) e Hospital da Restauração, hospitais terciários, de caráter estadual. O projeto foi aprovado pelo Comitê de Ética em Pesquisa do IMIP, conforme parecer em 2 de novembro de 2002.

Para aprofundar a compreensão dos "núcleos de sentido" das mensagens contidas nas 47 entrevistas semi-estruturadas realizadas com 35 pediatras chefes de plantão, duas pediatras diretores de unidades, três pediatras e sete enfermeiras coordenadores setoriais, as técnicas de análise de conteúdo 24 foram submetidas ao que Minayo 25 denomina de "superação dialética", ou seja, os significados manifestos e latentes foram interpretados tendo como referência o contexto sócio-histórico desse grupo social. As entrevistas foram realizadas por duas pesquisadoras, médicas pediatras, de março a julho de 2003, em salas fornecidas pelos serviços, após contato telefônico para agendar sessão. Cada informante foi devidamente esclarecido sobre os objetivos do estudo, o caráter espontâneo da participação e o sigilo das informações, assinando o consentimento pós-informado. Dois médicos, chefes de plantão, em duas unidades de maior complexidade, faltaram ao encontro agendado.

Ao delinear o perfil dos respondentes, constatase que aproximadamente quatro quintos dos médicos pediatras e a totalidade dos profissionais de enfermagem são do sexo feminino. Os médicos apre- 
sentam maiores tempos médios de formado, de trabalho em serviços de urgência/emergência e de lotação na unidade onde foram entrevistados, independentemente do cargo. Nota-se, contudo, enorme variação em relação ao exercício profissional, já que a amplitude da distribuição do tempo inclui médicos chefes de plantão com 3 a 33 anos de formados. Comportamento semelhante é observado entre as enfermeiras, com 4 meses a 26 anos de conclusão do curso (Tabela 1).

O roteiro contemplou: tempo de formado, tempo de trabalho em urgência/emergência, tempo de inserção na unidade atual, percepções sobre as mudanças na atenção à saúde da criança durante o exercício profissional, dificuldades na organização atual da assistência à saúde da criança, papel que compete aos

Tabela 1

Distribuição dos informantes segundo profissão, e cargo, e sexo, tempo de formado, de trabalho em urgência e de trabalho na unidade de urgência/emergência. Recife, 2003

\begin{tabular}{|c|c|c|c|}
\hline Variáveis & $\begin{array}{l}\text { Chefia médica de plantão } \\
\qquad(\mathrm{N}=35)\end{array}$ & $\begin{array}{l}\text { Coordenação médica } \\
\qquad(\mathrm{N}=5)\end{array}$ & $\begin{array}{c}\text { Coordenação de enfermagem } \\
\qquad(\mathrm{N}=7)\end{array}$ \\
\hline Sexo feminino & $82,9 \%$ & $80 \%$ & $100 \%$ \\
\hline \multicolumn{4}{|l|}{ Tempo de formado (anos) } \\
\hline Tempo médio & 18,4 & 19,6 & 11,3 \\
\hline Amplitude da distribuição & $3-33$ & $13-26$ & $0,33-26$ \\
\hline \multicolumn{4}{|l|}{ Trabalha em urgência (anos) } \\
\hline Tempo médio & 15,3 & 16,8 & 6,6 \\
\hline Amplitude da distribuição & $0,25-32$ & $10-26$ & $0,25-21$ \\
\hline \multicolumn{4}{|l|}{ Trabalha na unidade (anos) } \\
\hline Tempo médio & 11,2 & 11,2 & 8,6 \\
\hline Amplitude da distribuição & $0,25-32$ & $2-23$ & $0,25-25$ \\
\hline
\end{tabular}

profissionais dos serviços hospitalares de prontosocorro, opiniões sobre como a integralidade poderia se concretizar na atenção à saúde infantil e sentimentos frente à prática na urgência/emergência. A duração de cada sessão dependeu da disponibilidade do entrevistado, sendo necessário, em geral, em torno de 25 minutos. As entrevistas foram gravadas e todos os seus conteúdos transcritos.

O material de campo foi cuidadosamente preparado, sendo feita uma leitura minuciosa e repetida das entrevistas para compreender e agrupar as idéias nucleares em relação à unidade de registro, aqui, os temas que expressam as vivências e as percepções por meio das quais os profissionais construíram os seus sentimentos diante da prática. A unidade de contexto foi a entrevista como um todo. Buscou-se deslindar a articulação entre as categorias analíticas estabelecidas: sentimentos - percepção das situações de trabalho à luz de uma possível satisfação das necessidades; e atitudes - respostas diante das situações de trabalho; e as categorias empíricas elaboradas com base nos significados relevantes presentes nos discursos. Constituíram-se três corpus, 24 isto é, três conjuntos diferenciados de discursos: médicos chefes de plantão; médicos diretores de unidades e médicos coordenadores setoriais; e enfermeiras coordenadoras setoriais.

O processo de aprofundamento da análise, por meio da "leitura transversal", possibilitou a identificação das principais tendências nos corpus. Para ampliar a visão recorreu-se ao trabalho de três avaliadores. A presença de determinados temas foi ressaltada qualitativamente e, no exame comparativo, o destaque dado a fragmentos de discursos pressupõe a apreensão do sentido desse fragmento na totalidade do pensamento do qual foi separado. A inclusão de vários serviços, representando tipos distintos de demanda, modelos diferentes de organização e especificidades na execução do trabalho, ao permitir a apreensão de variações, potencializa a capacidade de evidenciar de modo mais seguro os aspectos essenciais do problema avaliado, aumentando a utilidade de seus resultados. 


\section{Resultados e Discussão}

\section{Percepção de desgaste ocupacional}

Nos relatos desses profissionais convivem sentimentos díspares: o cansaço, o esgotamento, a angústia, a impotência e a revolta, devido à sobrecarga provocada pelo excesso de demanda e pelas limitações dos recursos diante de situações que envolvem risco de vida, permeados pela satisfação de gostar do que fazem e pela consciência da própria utilidade. Apesar da tensão emocional constante e da vontade de desistir, visto que os problemas presentes no cotidiano lhes parecem maiores do que os recursos disponíveis para resolvê-los, os chefes de plantão e enfermeiras desfrutam a sensação de dever cumprido quando conseguem, sobrepondo-se às dificuldades, recuperar crianças que chegaram muito graves, recebendo em troca a satisfação da mãe, da família.

"[...] a gente está aqui atendendo, a gente vê crianças que chegam graves, então, o que a gente sente quando criança sai melhor, a mãezinha sai satisfeita, a gente tem aquele sentimento assim de dever cumprido. [...] outras vezes a gente não consegue salvar, ou tem que transferir uma criança e não consegue, então, nessas horas a gente se sente tão pequena. Então muitas vezes é angustiante, sai estressada do plantão, sai com aquela tristeza de ter feito tão pouco, porque a gente tem poucas ferramentas, às vezes, tem poucas ferramentas na mão para fazer". (Chefe de plantão).

Esses profissionais mantêm uma árdua relação com o ambiente externo, uma vez que as limitações no acesso e/ou as deficiências de atenção à criança na rede hierarquizada de serviços de saúde se refletem na organização interna do trabalho e representam fonte sistemática de desgaste. De um lado, a sobrecarga mental26 pela demanda crescente para resolver problemas de saúde que, da perspectiva técnica, poderiam ser solucionados no nível primário, acentua o conflito entre a exigência do atendimento qualificado das crianças cujos agravos necessitam de cuidado imediato e as possibilidades reais de satisfazer esses requisitos. Os chefes de plantão se sentem pressionados pelo receio de que casos graves passem desapercebidos e permaneçam por tempo prolongado na sala de espera, enquanto atendem a demanda ambulatorial.

"O volume (da demanda) me gera muita ansiedade, porque você tem um momento de pico, você tem crianças que esperam quatro, cinco horas pelo atendimento, então das dez. que estão lá fora, uma realmente ou duas deve ser emergência, quem faz essa avaliação? O funcionário lá da frente?". (Chefe de plantão).

De outro lado, o estresse crônico a que estão submetidos diante das dificuldades para realizar os encaminhamentos necessários, sendo instados a diminuir os sofrimentos e controlar os riscos de casos graves, incompatíveis com os recursos disponíveis. Por conta disso, incumbe-lhes tomar decisões delicadas que mobilizam forte carga afetiva, uma vez que convivem com a angústia dos familiares, necessitando lhes dar suporte em uma experiência emocional crítica, 7,8,20 além de fazer adaptações radicais no processo de trabalho, quase sempre sob condições bastante precárias.

"Eu me vejo angustiado, muito angustiado, extremamente angustiado. Tem plantão que a gente sai com o coração na mão, chega um ponto que, às vezes, quando aparece uma vaga (de UTI), aí vai pesar quem está menos grave. Quando a gente olha para o que saiu e os paizinhos olham pra gente, isso dói". (Chefe de plantão).

"[...] a gente não tem uma aparelhagem boa para atender uma emergência maior, aí traz o menino para enfermaria, entuba, ajeita e bota no ambu, cadê o respirador depois para botar? Fica aquela angústia, não tem vaga para encaminhar. Eu mesma já fiquei aqui um plantão inteiro "ambuzando" um menino, no fim do plantão consegui uma vaga de UTI e ele morreu antes de sair daqui. Essa parte eu acho horrível, você fica se sentindo completamente impotente: o que danado estou fazendo aqui?". (Chefe de plantão).

Com as equipes de pronto-socorro lidando com situações que encerram risco de morte, cujos procedimentos diagnósticos e terapêuticos exigem observações e reavaliações constantes, além de decisões rápidas e acertadas, esses profissionais também se mostram muito angustiados pela superposição de atribuições, a qual aumenta o conflito entre o que ao sentimento de carga mental têm como ponto comum a impossibilidade de cumprir adequadamente as tarefas previstas. 26

"[...] pela falta de pessoal você tem que fazer três coisas ao mesmo tempo, decidir quem vai, quem não vai, o que vai acontecer, isso estressa muito, isso está dificultando a assistência, você tenta fazer o melhor, mas nem sempre consegue. Numa grande 
porcentagem das vezes você sabe que não

fez o seu melhor". (Chefe de plantão).

A necessidade de ter múltiplos vínculos empregatícios devido à acentuada lacuna entre os baixos salários e as aspirações a um determinado padrão de vida compromete a qualidade da assistência e a saúde física e mental de todos os componentes da equipe de saúde. $26 \mathrm{O}$ sentimento de desqualificação das distintas categorias profissionais fica explicitado quando se compara a remuneração recebida com o nível de exigência, a responsabilidade e o esforço empregado em um processo de trabalho sistematicamente atravessado pelas tensões pessoais, organizacionais e sociais. $7,8,11$

"Muito cansada, muito cansada porque só trabalho em urgências, eu trabalho em três hospitais, cansada pelo número de empregos, pela grande demanda, pela remuneração que eu acho baixíssima, realmente, para um médico de urgência trabalhar tanto assim e ganhar tão pouco" (Chefe de plantão).

"[...] as pessoas estão muito estressadas, vai desde o auxiliar, a enfermeira, pela sobrecarga de trabalho, pela questão salarial mesmo. Você não trabalha em três por opção, seria ideal se pudesse ganhar o suficiente com um emprego, aí você poderia se dedicar mais, poderia produzir melhor". (Enfermeira, coordenadora do setor).

O conflito entre os aspectos positivos e negativos da experiência é identificado mais uma vez quando os depoimentos dos chefes de plantão deixam patente que a motivação para dar o melhor de si, fazer o melhor que podem e a consciência de que a equipe também deseja melhorar é, algumas vezes, entremeada pelo temor de que devido ao cansaço, ao estresse crônico, possam vir a cometer alguma omissão, algum engano que comprometa a sobrevivência do paciente. Outros estudos também encontraram essa preocupação, advinda da consciência de ser responsável por vidas humanas.7,8

"[...] eu tento fazer o melhor que eu posso, assim, eu devo errar bastante, mas é assim sem querer, o tal do erro sem querer não é negligência. Dentro da estrutura que a gente está, eu tento fazer o melhor que eu posso". (Chefe de plantão).

"Como profissional eu acho que às vezes a gente trabalha muito, tem que ter assim uma velocidade de atendimento para dar conta. Tenho receio que passe alguma doença que está na sua mão, mas, você não viu, que você sabia dar o diagnóstico, você conhece tudo, mas devido à quantidade de crianças, então realmente fica difícil, se Deus quiser não é uma coisa grave!". (Chefe de plantão).

Nesta pesquisa, as dificuldades de articulação dos trabalhos parcelares fazem com que as relações no interior da própria equipe multidisciplinar sejam permeadas pelas cobranças, com as enfermeiras se ressentindo mais dessas pressões. De acordo com Campos, 27 nas organizações de saúde mais hierarquizadas, observa-se uma agregação vertical de profissões e cada categoria profissional elabora os seus próprios regulamentos, objetivos e normas, sendo comum o desentrosamento entre as várias linhas de trabalho.

"Ultimamente me sinto estressada, sufocada, não só eu como enfermeira-chefe, mas, toda equipe está estressada, isso realmente me dá uma angústia profunda, porque a gente quer prestar uma assistência qualificada, com competência, essa demanda, essa superlotação, a gente não conseguir dar aquela assistência que realmente quer prestar. Eu acho que a enfermagem é muito cobrada, tanto pela equipe médica como pela população, a gente é muito cobrada e isso estressa demais o profissional de enfermagem". (Enfermeira, coordenadora do setor)

A falta de suporte institucional que não permite ter maior autonomia e controle sobre o ambiente de trabalho, elemento importante na gênese do desgaste físico e emocional de profissionais, 5-7,28 ausente apenas nos relatos dos dois pediatras diretores de unidades, é mais valorizada pelas enfermeiras 29 e médicos coordenadores setoriais, os quais se sentem impossibilitados de interferir e mudar as condições de trabalho de acordo com as necessidades. Portanto, constrangidos por políticas e práticas organizacionais que regulam a gestão do desempenho.

"A minha grande dificuldade no momento é recursos humanos. Quando eu entrei tinha vinte e três auxiliares que são contratadas pela Prefeitura, mas tem várias pessoas que estão se aposentando. A demanda aumentou, com uma quantidade que era insuficiente, imagine agora, inclusive aqui eu não tenho enfermeiros para cobrir todos os dias da semana: vinte quatro horas do sábado e do domingo eu não tenho enfermeiro, isso já faz muito tempo, eu não tenho enfermeiro terça-feira à noite, eu só tenho duas enfermeiras diaristas que cobrem aqui (enfermarias) e lá fora". (Enfermeira, 
coordenadora do setor).

Delineia-se o reconhecimento de que os riscos associados aos serviços de emergência são derivados do sofrimento produzido pela angústia que perpassa às situações de trabalho. Nesse contexto, os chefes de plantão asseveram que o adoecimento é uma experiência amplamente compartilhada.

"[...] existem riscos inerentes à emergência em relação ao estresse, já que você lida com a angústia da família, lida com a angústia de ter que fazer tudo às pressas, lida com a angústia de ter um transporte que esteja a seu dispor, lida com a angústia de ter um serviço para onde você possa referir quando você não tem vaga, lida com a angústia de não ter um lugar para colocar a criança quando está lotado lá dentro. Então você lida com muitas angústias e, além disso, tem que fazer o seu serviço bem, tocar rápido para que tudo funcione". (Chefe de plantão).

"Eu peguei o plantão hoje com 50 pacientes quando nós só temos 25 vagas e isso é todo santo dia, todo santo dia, isso sobrecarrega os profissionais, todos estão doentes, todos os colegas estão doentes, sem exceção, todos, de todos os plantões". (Chefe de plantão).

\section{Atitudes diante do trabalho}

Os trabalhadores de saúde desenvolvem relações afetivas com aqueles a quem cuidam, mas as mediações impostas pela profissionalização do cuidado, vínculos do trabalho, tarefas, regras, transferências, óbitos, alimentam as tensões e ambigüidades relativas à tênue distinção entre envolver-se profissional e não pessoalmente na ajuda aos pacientes e seus familiares, exacerbando a ansiedade ou estimulandoos à racionalização por meio do distanciamento emocional, do endurecimento $5,7,9$. Batista e Codo 30 enfatizam que quanto maior a defasagem entre o "trabalho como deve ser" e a "realidade do trabalho", maior será o investimento afetivo e cognitivo realizado, portanto, maior será o sofrimento no ambiente laboral.

"Desgastante demais, a gente fica sofrendo, a gente sofre por a gente, a gente sofre pelos outros, sabe, a gente entende a frieza de algumas pessoas, porque você termina ficando frio ou então você fica louco. [...] você termina ficando frio, termina ficando, não é que trate mal, é sem tratar bem, você diz assim, é dor de ouvido, bota o otoscópio, olha o ouvido e passa a receita, a criança não é o ouvido, é isso, se diminuísse a pressão o trabalho seria bem feito". (Chefe de plantão).

A oferta e o consumo de saúde estão intimamente relacionados, de tal modo que corresponder às expectativas da clientela é um dos maiores desafios para a organização da assistência. ${ }^{1}$ Os limites e potencialidades operacionais dos serviços são confrontados diariamente com as necessidades dos usuários, abrindo espaço para questionamentos e reivindicações atinentes ao processo de trabalho que, em muitas circunstâncias, podem provocar atritos entre os profissionais e os responsáveis pelas crianças. 7,8

"[...] difícil porque a gente se expõe na realidade, corre o risco de ser agredido porque demorou a atender, quando na realidade você está atendendo outro, quando na realidade você tem três pra atender ao mesmo tempo, decidir quem vai, decidir quem não vai, o que vai acontecer". (Chefe de plantão).

A sensação de desamparo diante das condições de trabalho e as percepções do desrespeito da população com o médico, expondo-o em algumas situações ao risco de agressão e até mesmo de indiciamento judicial, reforçam a falta de esperança e aumentam a vulnerabilidade física e social.7,8 A dinâmica da integração usuário-serviço requer o estabelecimento do diálogo e do respeito mútuo, mas a violência interpessoal é um ataque à dignidade do profissional que desperta a desconfiança e altera o ânimo para o trabalho, alimentando atitudes negativas devido ao desgaste diário ao qual é submetido.

"Já fui mais otimista, hoje em dia estou sem ver a possibilidade de melhora a longo prazo, porque faltam condições, cada dia que passa a gente é mais exigido, até muitas vezes a gente corre o risco de ser processado, né, tem caso de colega que está respondendo um processo, quer dizer, a tudo isso a gente se vê sujeito, eu já fui mais otimista, hoje em dia eu procuro levar fazendo a minha parte". (Chefe de plantão).

"[...] a gente olha para o paciente, ele é um possível inimigo, e o paciente olha para o médico, ele é um possível ganha pão: se escorregar, eu boto na justiça". (Chefe de plantão).

Em algumas circunstâncias é possível constatar a falta de perspectiva concreta em relação às possibilidades de ocorrerem mudanças nessa situação e, em 
casos extremos, identificados principalmente entre os pediatras chefes de plantão com menor tempo de formados, esboça-se o sentimento de perda da relação com o trabalho que se traduz, de modo concomitante, na vontade de desistir e no menor envolvimento com a solução dos problemas. Nas áreas de saúde e educação, pesquisas têm demonstrado que a maior concentração de profissionais insatisfeitos é encontrada nos primeiros anos de formado, tendendo a cair com o transcurso do tempo. ${ }^{12}$

É interessante notar que embora de modo genérico esses profissionais adotem estratégias centradas na emoção para lidar com o desgaste ocupacional, é perceptível a influência do tempo de formado nas alternativas utilizadas para continuar convivendo com a situação estressante. Aqueles com menor tempo recorrem ao escape, ao distanciamento e à atenção seletiva, enquanto os mais velhos, com o propósito de manter a esperança e o otimismo, atenuam a importância dos fatores contextuais específicos. Essas atitudes tendem a aumentar o desgaste emocional, apesar das diferenças no desenvolvimento de novas pautas de conduta. 28

"Me sinto cansada, estressada, muitas vezes com vontade de desistir, vontade de deixar tudo, mas é o tipo da coisa, você começar outra coisa tudo do início fica complicado". (Chefe de plantão, cinco anos de formada).

"Eu fico estressada, a emergência está abalando a minha saúde, porque eu fico extremamente estressada, a demanda é muito grande para os profissionais, é uma coisa muito cansativa, quando chega um paciente grave, a gente tira o paciente da emergência e precisa internar, precisa um leito hospitalar e não tem. Outra coisa muito estressante é porque raramente você consegue uma vaga de UTI. [...] Às vezes me frustro muito, sabe, com isso de emergência, tanto que eu mesma já disse, não reclamo mais, não boto mais nada no livro, porque não adianta". (Chefe de plantão, seis anos de formada).

Assim, ainda que à revelia das dificuldades, dos sofrimentos, das tristezas, das decepções e do estresse, esses profissionais não tenham perdido os vínculos afetivos com o trabalho, são principalmente aqueles que têm um maior tempo de formados que afirmam que voltariam a fazer as mesmas escolhas em relação ao exercício do trabalho cotidiano, que enxergam os avanços obtidos e continuam tendo esperança e disponibilidade para a árdua construção de um modelo de assistência à saúde.

"Eu me sinto feito aquele beija-flor do Betinho, que vocês já viram a propaganda, não sei se vocês estão lembradas, o beijaflor tentando apagar o incêndio da floresta, carregando aquelas gotinhas de água. Eu me sinto, assim, como o beija-flor do Betinho, eu tento ao longo da minha carreira me empenhar o máximo possível para fazer também o melhor possível a minha parte. Não é grande coisa, mas, eu acho que se cada um fizesse o melhor possível a sua parte, a gente conseguiria muita coisa". (Chefe de plantão, 28 anos de formada).

\section{Conclusões}

O estresse crônico é vivenciado de modo muito mais intenso pelos pediatras que respondem pela chefia dos plantões e pelos pediatras e enfermeiras que coordenam os setores de pronto-socorro, ou seja, por aqueles que prestam assistência à criança. Entretanto, na dependência da categoria profissional e do cargo, à medida que as expectativas acerca da profissão, da organização e do desempenho pessoal são contrastadas com a realidade, os sentimentos de que o trabalho exige demais de si mesmo, de desgaste e esforço ao lidar com a clientela, de frustração e insatisfação, além de persistente sensação de cansaço, conformam diferentes amálgamas. Por isso, diante de uma situação de trabalho que é difícil de suportar, mas que ainda desperta satisfação pela inegável importância da tarefa a ser cumprida, a contínua tensão entre prazer e sofrimento repercute de modo diferenciado sobre o envolvimento pessoal nas atividades profissionais. $5,10,12$

O sofrimento é uma reação à persistência de condições desfavoráveis ao ser humano, logo, constitui-se em uma dimensão contingente da vida e do trabalho. As tentativas para sua superação, entretanto, podem resultar em soluções que são mais ou menos favoráveis à qualidade de vida dos profissionais e ao trabalho executado, na dependência de serem fruto de um enfrentamento mais afetivo dos problemas ou do distanciamento emocional que é associado ao adoecimento e à inibição de relações afetivas com os pacientes e seus familiares.5,10,12 Apesar de continuar existindo comprometimento com o ofício, até mesmo entre os que se mostram mais insatisfeitos e desenvolvem atitudes mais negativas diante das situações de trabalho, esboça-se uma tendência para a exaustão emocional, o sentimento de não querer dar mais e/ou o sentimento de inade- 
quação e fracasso, os quais podem levar à desistência, a perda da relação com o trabalho.

Neste estudo, semelhante ao observado em outros, o tempo de formado do médico $7,8,12$ é um importante mediador das respostas ao sofrimento e as perdas provocadas pelas limitações organizacionais, percepções de desvalorização social do trabalho e possibilidade recorrente da violência nos serviços, as quais contrariam as expectativas de qualificação da assistência e de dignidade no trabalho. Os mais jovens, motivados para propor novos projetos, se inseriram no mercado de trabalho sob a crise do rebaixamento salarial e da perda do status pelo médico, com dificuldade para lidar com o sofrimento, tendem à desesperança, visto que não parecem vislumbrar maiores possibilidades de melhoria nas condições de trabalho. Os mais velhos sofrem, mas continuam esperando uma solução, talvez porque se tornaram mais complacentes, avaliam as situações estressantes recorrendo às comparações positivas, extraem aspectos positivos de experiências negativas ou fortaleceram o sentimento do trabalho como missão.

Algum dos sentimentos constituintes do burnout pode estar presente de modo intermitente, assim, sorrateiramente a síndrome avança com o tempo e como alertam Codo e Vasques-Menezes (2000: 254)5

"... a desistência não tem uma só forma, ao contrário, comparece como um monstro de mil cabeças, quando uma é cortada outra toma o seu lugar".

Portanto, é preciso identificar caminhos para modificar essa realidade, sendo fundamental que a prevenção e o tratamento do burnout sejam abordados como problemas coletivos e organizacionais e não como um problema individual.5,6 Atualmente, está sendo priorizada a estratégia de melhoria do suporte social no trabalho por meio dos grupos de

\section{Agradecimentos}

Ao Ministério da Saúde pelo financiamento da pesquisa. discussão, com o intuito de estimular a cooperação entre companheiros, mas começa a despontar o recurso ao desenvolvimento organizacional como processo dialógico de transformação das condições de realização do trabalho.

De acordo com Sato, 6 o planejamento/replanejamento do trabalho por meio das negociações cotidianas é parte do conjunto de estratégias que visam a promoção e a prevenção em saúde no ambiente laboral. Desse modo, é possível estabelecer compromissos para conciliar as demandas provocadas pelos interesses conflitantes que perpassam as situações de trabalho, quais sejam, da organização, das tarefas, dos cargos, dos setores de trabalho, das pessoas e de seus grupos sociais, entre outros. Cabe lembrar que os trabalhadores com base na experiência e no conhecimento construído na prática já replanejam, informalmente, para tornar factível de execução, aquilo que foi planejado por outrem, o que explica a diferença entre o trabalho prescrito e o real.

Em um contexto em que a Política Nacional de Humanização, formulada pelo Ministério da Saúde, 22 ressalta o "compromisso com a ambiência, melhoria das condições de trabalho e de atendimentos", torna-se fundamental estar atento ao fato de que o planejamento/replanejamento do trabalho visando a promoção da saúde do trabalhador requer, além das micro-negociações de interesses conflitantes no contexto local, a participação dos níveis federal, estadual e municipal de gestão do SUS, das diferentes instâncias de direção, dos usuários e dos sindicatos e conselhos de classe, conformando amplas redes de interações voltadas para a tradução das diretrizes políticas em formas concretas de valorização dos profissionais de saúde e, por conseqüência, de qualificação da prestação de serviços. 


\section{Referências}

1. Pinheiro R. As práticas do cotidiano na relação oferta e demanda dos serviços de saúde: um campo de estudo e construção da integralidade. In: Pinheiro R, Mattos RA, organizadores. Os sentidos da integralidade na atenção e no cuidado à saúde. Rio de Janeiro: Universidade Estadual do Rio de Janeiro; 2001. p. 65-112.

2. Merhy EE. Em busca do tempo perdido: a micropolítica do trabalho vivo em saúde. In: Merhy EE, Onocko R, oranizadores. Agir em saúde: um desafio para o público. 2. ed. São Paulo: Hucitec; 2002. p. 71-112.

3. Vaitsman J. Cultura de organizações públicas de saúde notas sobre a construção de um objeto. Cad Saúde Pública 2000; 16: 847-50.

4. Seligmann-Silva E. Saúde mental e automação: a propósito de um estudo de caso no setor ferroviário. Cad Saúde Pública 1997; 13 (Supl 2): 95-109.

5. Codo W, Vasques-Menezes I. O que é burnout? In: Codo W, organizador. Educação: carinho e trabalho. 2. ed. Petrópolis: Vozes; 2000. p. 237-54.

6. Sato L. Prevenção de agravos à saúde do trabalhador: replanejando o trabalho através das negociações cotidianas. Cad Saúde Pública 2002; 18: 1147-66.

7. Flórez-Lozano JA. Salud mental del médico: prevención y control del burnout. Salud Global 2003; 3: 2-7.

8. Escriba-Agüir V, Bernabé-Muñoz Y. Exigencias laborales psicológicas percibidas por médicos especialistas hospitalarios. Gac Sanit 2002; 16: 487-96.

9. Farber BA. Crisis in education - stress and burnout in the American teacher. San Francisco (Oxford): Jossey-Bass; 1991.

10. Vasques-Menezes I, Gazzotti AA. A si mesmo como trabalho. In: Codo W, organizador. Educação: carinho e trabalho. 2. ed. Petrópolis: Vozes; 2000. p. 368-83.

11. Odelius CC, Ramos F. Remuneração, renda, poder de compra e sofrimento psíquico do educador. In: Codo W, organizador. Educação: carinho e trabalho. 2. ed. Petrópolis: Vozes; 2000. p. 338-54.

12. Soratto L, Pinto RM. Atitude no trabalho e burnout. In Codo W, organizador. Educação: carinho e trabalho. 2. ed. Petrópolis: Vozes; 2000. p. 278-81.

13. Borges LO, Argolo JCT, Pereira ALS, Machado EAP, Silva WS. A síndrome de burnout e os valores organizacionais: um estudo comparativo em hospitais universitários. Psicologia: Ref Cri 2002; 15: 189-200.

14. Figueroa NL, Schufer M, Muiños R, Marro C, Coria EA. Um instrumento para a avaliação de estressores psicossociais no contexto de emprego. Psicologia: Ref Cri 2001; 14: 653-9.

15. Felton JS. Burnout as a clinical entity - its importance in health care workers. Occup Med (London) 1998; 48: 237 50 .

Recebido em 21 de dezembro de 2004

Versão final em 13 de maio de 2005

Aprovado em 3 de agosto de 2005
16. Lipton H, Everly-Jr GS. Mental health needs for providers of emergency medical services for children: a report of a consensus panel. Prehosp Emerg Care 2002; 6: 15-21.

17. Boudreaux E, Mandry C. Sources of stress among emergency medical technicians. Part I: What does the research say? Prehosp Disas Med 1996; 11: 296-301.

18. Chen SM, McMurray A. "Burnout" in intensive care nurses. J Nur Res 2001; 9: 152-64.

19. Cardigni G, Althabe M, Vega L. El intensivista pediátrico: ejerciendo la especialidad. Arch Argen Pediatr 1998; 96: 363-68.

20. Sociedade Internacional de Oncologia Pediátrica. Comitê Psicossocial. Manual de orientações psicossociais em oncologia pediátrica. São Paulo; Comitê Pediátrico da Sociedade Brasileira de Psico-Oncologia; 2000. Disponível em URL: http://www.sbpo.com.br/producao/siop.pdf [2004 julho 13].

21. Benevides-Pereira AMT. O estado da arte do burnout no Brasil. Rev Eletr InterAção Psy 2003; 1: 4-11.

22. Ministério da Saúde. Secretaria Executiva. Núcleo Técnico da Política de Humanização. Por que uma Política Nacional de Humanização? Disponível em URL: Http://portal.saude. gov.br/saude/area.cfm?id_area=390 [2004 agosto 10].

23. Hartz MZA. Explorando novos caminhos na pesquisa avaliativa das ações de saúde. In: Hartz MZA, organizadora. Avaliação em saúde: dos modelos conceituais à prática da análise de implantação de programas. Rio de Janeiro: FIOCRUZ; 1997. p. 19-28.

24. Bardin L. Análise de conteúdo. Lisboa: Edições 70; 1977.

25. Minayo MCS. Fase de análise ou tratamento do material. In: O desafio do conhecimento: pesquisa qualitativa em saúde. 2. ed. São Paulo: Hucitec; 1993. p. 97-247.

26. Soratto L, Pinto RM. Burnout e carga mental no trabalho. In: Codo W, organizador. Educação: carinho e trabalho. 2. ed. Petrópolis: Vozes; 2000. p. 282-92.

27. Campos GWS. Subjetividade e administração de pessoal: considerações sobre modos de gerenciar trabalho em equipes de saúde. In: Merhy EE, Onocko R, organizadores. Agir em saúde: um desafio para o público. 2. ed. São Paulo: Hucitec; 2002. p. 229-66.

28. Tamayo MR. Exaustão emocional: relações com a percepção de suporte organizacional e com as estratégias de coping no trabalho. Estudos Psicol 2002; 7: 37-46.

29. Fernandes JD, Ferreira SL, Albergaria AK, Conceição FM. Saúde mental e trabalho feminino: imagens e representações de enfermeiras. Rev Latinoam Enferm 2002; 10: 199-206.

30. Batista AS, Codo W. Crise de identidade e sofrimento. In: Codo W, organizador. Educação: carinho e trabalho. 2. ed. Petrópolis: Vozes; 2000. p. 60-85. 